\title{
Relationship between life satisfaction and sympathovagal balance in healthy elderly males at home at night
}

\author{
Kohzoh Yoshino ${ }^{1 *}$, Tomoko Morimoto ${ }^{2}$, Takahiro Itagaki $^{3}$, Shigetaka Iketani ${ }^{3}$, Masami Nagata $^{4}$, \\ Morihiro Tsujishita ${ }^{4}$ \\ ${ }^{1}$ Health Research Institute, National Institute of Advanced Industrial Science and Technology (AIST), Osaka, Japan; \\ *Corresponding Author: yoshino-k@aist.go.jp \\ ${ }^{2}$ Faculty of Nursing, Nara Medical University, Nara, Japan; \\ ${ }^{3}$ Health Management and Development Center, Osaka, Japan; \\ ${ }^{4}$ Faculty of Rehabilitation Nursing, Konan Women's University, Hyogo, Japan;
}

Received 18 September 2012; revised 20 October 2012; accepted 27 October 2012

\begin{abstract}
The aim of this study is to clarify how well-being correlates with autonomic nervous system (sympathovagal) balance in healthy elderly males at home at night awake and resting. The RR-interval and body acceleration of 39 healthy elderly male subjects were recorded with an ambulatory device for 72 hours. The normalized high-frequency $(0.15-0.4 \mathrm{~Hz})$ power (HFnu) of RR-interval variability (sympathovagal balance index) was calculated from $10 \mathrm{~min}$ long data sets that satisfied all of the following conditions: 1) average body acceleration was less than 30 mG, 2) the subject was at home, 3) the subject was awake, and 4) more than 95 percent of the time-series of instantaneous heart rate was within 40 to 160 [bpm]. Subjects recorded their subjective well-being level, including life satisfaction level, on a Visual Analogue Scale (VAS) questionnaire. We investigated the correlation between the subjective well-being level and mean HFnu. A significant negative correlation between life satisfaction level and mean HFnu ( $r=-0.47, p=0.004)$ was observed. This result implies that sympathovagal balance becomes the predominant state of the sympathetic nervous system in healthy elderly males with relatively high life satisfaction while at home at night awake and resting.
\end{abstract}

Keywords: Quality of Life; Psychophysiological Measures; Autonomic Nervous System; Heart Rate Variability; Happiness; Aged; Home

\section{INTRODUCTION}

To design home environments properly so that elderly people can live in health mentally and physically, it is necessary to reveal the relationship between the mind and body of elderly people during daily life in their homes. Finding out the relationship between psychological and physiological states in daily life is important for knowing the effect of psychological states on health [1]. It was reported that negative psychological states such as depression and anxiety increase the risk of developing coronary heart disease [2]. Many findings on the relationship between positive emotion in daily life and physical health are reported [3]. For example, subjects with a more positive emotional style had a reduced risk of developing respiratory illness in response to rhinoviruses and influenza viruses [4]. In addition, it was reported as a result of a cohort study that subjects with greater emotional vitality characterized by a sense of energy and positive well-being were at reduced risk for coronary heart disease [5].

Keeping sympathetic and parasympathetic nervous system activity balanced properly is important for health. Heart failure is related to elevated sympathetic nerve activity [6]. Mental and physical inactive states are related to the parasympathetic nervous system being in a too predominant state. Balance in autonomic nervous system activity (sympathovagal balance) in daily life can be measured with a heart rate variability monitor [7]. $\mathrm{LF} / \mathrm{HF}$, which is the power ratio of the low-frequency band (LF: $0.04-0.15 \mathrm{~Hz}$ ) and high-frequency band (HF: $0.15-0.4 \mathrm{~Hz})$ of the frequency spectrum of the RR interval of electrocardiogram, and HFnu, which is the normalized value of the power of the HF band, are used as indices of autonomic nervous system activity balance [8-10]. A high value of HFnu means that balance be- 
comes the predominant state of the parasympathetic nervous system.

The factors affecting balance in autonomic nervous system activity are not only the psychological state but also physical exertion, which increases sympathetic nervous system activity. Therefore, to find the relationship between the psychological state and the balance in the autonomic nervous system, the effects of physical exertion need to be eliminated. One method for doing so measures body acceleration to assess the daily activity level, and data higher than a certain threshold is eliminated from analysis [11-13].

Bhattacharyya et al. [14] examined the relationship between positive emotion and balance in autonomic nervous system activity for elderly patients suspected of coronary artery disease. As a result, it was shown that patients with positive emotion in daily life had a higher HFnu value with statistical significance and a predominant parasympathetic nervous system. Patients with coronary artery disease have a sympathetic nervous system in a more predominant state than do healthy people [15]. Therefore, this relationship between balance in autonomic nervous system activity and positive emotion might not be applied to healthy subjects. In addition, in this study, physical activity was not recorded while heart rate variability being measured but rather recorded by being remembered. Also, the relationship between the subjective well-being level of healthy elderly people and balance in autonomic nervous system activity in daily life has not yet been revealed. Therefore, in this study, for healthy elderly males, heart rate variability and body acceleration in daily life were measured at the same time, and the relationship between balance in autonomic nervous system activity and the subjective well-being level in daily life, including life satisfaction, with low physical activity at home was investigated. Balance in the autonomic nervous system activity changes not only by one's psychological state and physical exertion but also by the effects of circadian rhythm [16] and the present environment. Therefore, in this study, the time period for when the subjects stayed awake at night in their homes was focused on. Our hypothesis is that the more satisfied with life a healthy elderly male is, the more the sympathetic nervous system is predominant when he stays awake at night at home and physical activity level is relatively low.

\section{METHODS}

\subsection{Participants}

Normal healthy elderly male subjects ( $\mathrm{N}=39$, age: 61 to 79 years) participated in this experiment. None of the subjects had a history of cardiovascular, respiratory, brain, or mental disease. None of the subjects were tak- ing any medication at the time. All subjects provided their informed written consent as approved by the Ethical Committee on Human Research at Nara Medical University and the National Institute of Advanced Industrial Science and Technology.

\subsection{Daily Life Experiment}

Subjects intermittently wore an Active Tracer ambulatory device (AC-301, GMS, Japan) in a pouch at the waist for a total of 72 hours during daily life, including sleep, except when taking a bath or shower. This device records the RR-intervals of the electrocardiogram (heart rate variability) and body acceleration $10-\mathrm{cm}$ VAS.

\subsection{Data Analysis}

Many subjects stayed home from 19:00 to 21:00 and remained awake the entire time, so this time period was chosen to be the analysis object. First, the time period for days 1 to 3 was divided into windows 10 minutes in length (a total of 36 windows). Only the windows in which the following conditions, 1) to 4), were met were chosen to be analysis objects. For 1), average body acceleration must be lower than $30 \mathrm{mG}$ (when physical exertion is low). It was reported that $157.5 \mathrm{mG}$ is the optimum threshold value for discriminating between an active state and rest by measuring body acceleration [11]. We used the value $30 \mathrm{mG}$, which is five times smaller, in this study. For 2), the subject must be at home (judged by the registration paper). For 3 ), the subject must be awake (judged by the registration paper and body acceleration data). For 4), more than 95 percent of the time-series of instantaneous heart rate must be within 40 to 160 [bpm] (when $\mathrm{S} / \mathrm{N}$ ratio of signal is high).

HFnu calculation was carried out with the heart rate variability of the windows of the analysis objects. The power spectrum was calculated by applying a fast Fourier transform (FFT) to the RR-interval signal for each 10-min data set. The area (i.e., power) of the high-frequency component (HF: 0.15 to $0.4 \mathrm{~Hz}$ ) of the power spectrum was divided by the total power from which the very-low-frequency component (VLF: $<0.04 \mathrm{~Hz}$ ) had been subtracted in order to calculate the normalized HF power (HFnu). A high HFnu value implies that sympathovagal balance shifted towards parasympathetic dominance [8-10].

Four subjects who had no windows where all of the conditions were met were eliminated from the subsequent analysis. For each subject, the average values of HFnu were calculated from the windows of the analysis objects. HFnu was put on the vertical axis, and the well-being index for life satisfaction, health satisfaction, economic satisfaction, and calmness were put on the horizontal axis, then the correlation between the two was 
evaluated by calculating Pearson's correlation coefficients and their p-values.

\section{RESULTS}

The average value among the subjects for the average HFnu values of the analysis objects was $0.39 \pm 0.09$. Negative correlation with statistical significance was found between the average values for life satisfaction and the HFnu $(\mathrm{r}=-0.47, \mathrm{p}<0.01)$ (Figure 1). For other well-being indices, the average values were not statistically significant, but an inclination for negative correlation with calmness $(\mathrm{r}=-0.31, \mathrm{p}=0.06)$ was found (Table $\mathbf{1})$.

\section{DISCUSSION}

As a result of the experiment, an inclination was shown that the more satisfied with life a healthy elderly male was, the more the sympathetic nervous system was predominant while awake at home at night. In addition, in this analysis, body acceleration was measured at the same time, and time periods with a high value for body acceleration were eliminated from the analysis objects. Therefore, it is considered that the state of having a predominant sympathetic nervous system is due not to physical exertion but to the state of being mentally ac-

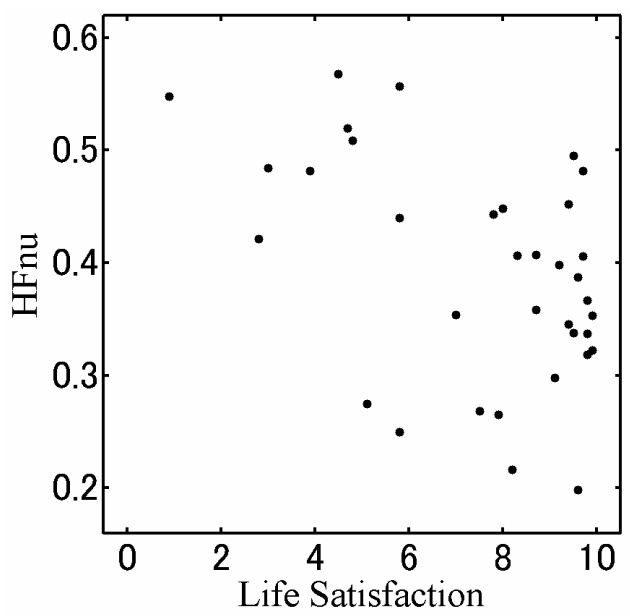

Figure 1. Scatter diagram between average values of life satisfaction and autonomic nervous system activity balance index HFnu $(\mathrm{r}=-0.47$, $\mathrm{p}<0.01)$.

Table 1. Pearson's correlation coefficients and the p-values of the average value of autonomic nervous system activity balance index HFnu and life satisfaction, health satisfaction, economic satisfaction, and calmness. ${ }^{*} \mathrm{p}<0.01$.

\begin{tabular}{ccccc}
\hline & $\begin{array}{c}\text { Life } \\
\text { sastisfaction }\end{array}$ & $\begin{array}{c}\text { Health } \\
\text { satsisfaction }\end{array}$ & $\begin{array}{c}\text { Economic } \\
\text { satisfaction }\end{array}$ & Calmness \\
\hline \multirow{2}{*}{ HFnu } & $\mathrm{r}=-0.47$ & $\mathrm{r}=-0.09$ & $\mathrm{r}=-0.18$ & $\mathrm{r}=-0.31$ \\
& $\mathrm{p}=0.004$ & $\mathrm{p}=0.57$ & $\mathrm{p}=0.29$ & $\mathrm{p}=0.06$ \\
\hline
\end{tabular}

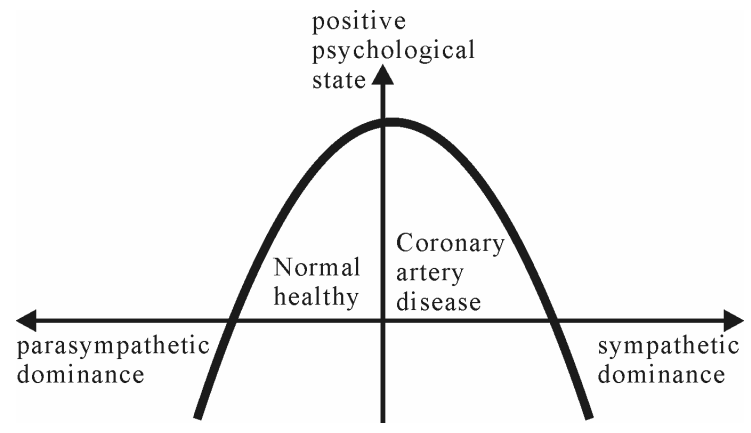

Figure 2. Hypothesis about the relationship between balance in autonomic nervous system activity and a positive psychological state.

tive and energetic.

In the previous study, it was reported that, in elderly patients suspected of coronary artery disease, the HFnu value of patients with strong positive emotion in daily life is higher with statistical significance and that the state of the parasympathetic nervous system of these patients is more predominant than that of patients with weak positive emotion [14]. Our result for this current study is contrary to the previous study. Patients with coronary artery disease have a sympathetic nervous system in a more predominant state than do healthy people. Actually, although the average age of elderly people suspected of coronary artery disease in the previous study [14] was $61 \pm 9$ years, which is younger than that in our study, the average HFnu value of the subjects while staying awake was $0.24 \pm 0.09$, which is far lower than the $0.39 \pm 0.09$ of our study result. Therefore, the relationship between the balance in autonomic nervous system activity and a positive psychological state (ex. life satisfaction) does not always apply to healthy people. As shown in the results of our current study and the previous study [14], the relational expression between balance in autonomic nervous system activity and a positive psychological state is not a monotonous function but is inferred to be an inverted U-shaped curve, as shown in Figure 2. In other words, for patients with coronary artery disease whose balance in autonomic nervous system activity is relatively inclined to a predominant state of the sympathetic nervous system, the more the balance is inclined to a predominant state of the sympathetic nervous system, the more the psychological state becomes inclined towards a negative direction. In contrast, for healthy people whose balance in autonomic nervous system activity is relatively inclined to a predominant state of the parasympathetic nervous system, the more the balance is inclined to a predominant state of the parasympathetic nervous system, the more they become mentally inactive, so the psychological state becomes inclined towards a negative direction. Therefore, it is considered to be best for the psychological state that 
balance in autonomic nervous system activity is not the result of the sympathetic or parasympathetic nervous systems being in too predominant a state but rather that the state is kept in moderate balance.

In this study, life satisfaction was evaluated with a single item, the VAS. In many studies, life satisfaction is evaluated with a paper questionnaire that contains multiple items such as a Life Satisfaction Index (LSI) [17] and a Satisfaction with Life Scale (SWLS) [18]. However, it was reported that evaluating well-being with a single item like in this study still has sufficient reproducibility and validity [19-20]. Therefore, life satisfaction was evaluated with a single-item question [21-23].

In summary, it is shown that the more satisfied with life a healthy elderly male is, the more predominant the sympathetic nervous system is when he stays awake at home at night and the physical activity level is relatively low.

\section{ACKNOWLEDGEMENTS}

This research was supported by Department of DAIWA HOUSE Indoor Environmental Medicine, Nara Medical University.

\section{REFERENCES}

[1] Pressman, S.D. and Cohen, S. (2005) Does positive affect influence health? Psychological Bulletin, 131, 925971. doi:10.1037/0033-2909.131.6.925

[2] Suls, J. and Bunde, J. (2005) Anger, anxiety, and depression as risk factors for cardiovascular disease: The problemas and implications of overlapping affective dispositions. Psychological Bulletin, 131, 260-300. doi:10.1037/0033-2909.131.2.260

[3] Dockray, S. and Steptoe, A. (2010) Positive affect and psychobiological processes. Neuroscience \& Biobehavioral Reviews, 35, 129-148. doi:10.1016/j.neubiorev.2010.01.006

[4] Cohen, S., Alper, C.M., Doyle, W.J., Treanor, J.J. and Turner, R.B. (2006) Positive emotional style predicts resistance to illness after experimental exposure to rhinovirus or influenza A virus. Psychosomatic Medicine, 68, 809-815. doi:10.1097/01.psy.0000245867.92364.3c

[5] Kubzansky, L.D. and Thurston, R.C. (2007) Emotional vitality and incident coronary heart disease: Benefits of healthy psychological functioning. Archives of General Psychiatry, 64, 1393-1401. doi:10.1001/archpsyc.64.12.1393

[6] Kleiger, R.E., Miller, J.P., Bigger Jr., J.T. and Moss, A.J. (1987) Decreased heart rate variability and its association with increased moratality after acute myocardial infarction. American Journal of Cardiology, 59, 256-262. doi:10.1016/0002-9149(87)90795-8

[7] Wilhelm, F.H. and Grossman, P. (2010) Emotions beyond the laboratory: Theoretical fundaments, study design, and analytic strategies for advanced ambulatory assessment. Biological Psychology, 84, 552-569.

\section{doi:10.1016/j.biopsycho.2010.01.017}

[8] Akselrod, S., Gordon, D., Ubel, F.A., Shannon, D.C., Barger, A.C. and Cohen, R.J. (1981) Power spectrum analysis of heart rate fluctuation: A quantitative probe of beat-to-beat cardiovascular control. Science, 213, 220222. doi:10.1126/science. 6166045

[9] Berntson, G.G., Bigger, J.T., Eckberg, D.L., Grossman, P., Kaufmann, P.G., Malik, M., Nagaraja, H.N., Porges, S.W., Saul, J.P., Stone, P.H. and Van der Molen, M.W. (1997) Heart rate variability: Origins, methods, and interpretive caveats. Psychophysiology, 34, 623-648. doi:10.1111/j.1469-8986.1997.tb02140.x

[10] Eckberg, D.L. (1997). Sympathovagal balance. Circulation, 96, 3224-3232. doi:10.1161/01.CIR.96.9.3224

[11] Mathie, M.J., Coster, A.C.F., Lovell, N.H. and Celler, B.G. (2003) Detection of daily physical activities using a triaxial accelerometer. Medical \& Biological Engineering \& Computing, 41, 296-301. doi:10.1007/BF02348434

[12] Yoshino K. and Matsuoka K. (2011) Correlation between mood and heart rate variability indices during daily life. Health, 3, 553-556. doi:10.4236/health.2011.39094

[13] Yoshino, K. and Matsuoka, K. (2012) Personal adaptive method to assess mental tension during daily life using heart rate variability. Methods of Information in Medicine, 51, 39-44. doi:10.3414/ME11-01-0027

[14] Bhattacharyya, M.R., Whitehead, D.L., Rakhit, R. and Steptoe, A. (2008) Depressed mood, positive affect, and heart rate variability in patients with suspected coronary artery disease. Psychosomatic Medicine, 70, 1020-1027. doi:10.1097/PSY.0b013e318189afcc

[15] Sinoway, L.I. and Li, J. (2005) A perspective on the muscle reflex: Implication for congestive heart failure. Journal of Applied Physiology, 99, 5-22. doi:10.1152/japplphysiol.01405.2004

[16] Ewing, D.J., Neilson, J.M.M. and Travis, P. (1984) New method for assessing cardiac parasympathetic activity using 24 hour electrocardiograms. British Heart Journal, 52, 396-402. doi:10.1136/hrt.52.4.396

[17] Neugarten, B.L., Havighurst, R.J. and Tobin, S.S. (1961). The measurement of life satisfaction. Journal of Gerontology, 16, 134-143.

[18] Diener, E., Emmons, R.A., Larsen, R.J. and Griffin, S. (1985) The satisfaction with life scale. Journal of Personality Assessment, 49, 71-75. doi:10.1207/s15327752jpa4901_13

[19] McDowell, I. (2006) Measuring health: A guide to rating scales and questionnaires. 3rd Edition, Oxford University Press, New York.

[20] De Boer, A.G.E.M., van Lanschot, J.J.B., Stalmeier, P.F.M., van Sandick, J.W., Hulscher, J.B.F., de Haes, J.C.J.M. and Sprangers, M.A.G. (2004) Is a single-item visual analogue scale as valid, reliable and responsive as multi-item scales in measuring quality of life? Quality of Life Research, 13, 311-320. doi:10.1023/B:QURE.0000018499.64574.1f

[21] Grant, N., Wardle, J. and Steptoe, A. (2009) The relationship between life satisfaction and health behavior: A cross-cultural analysis of young adults. International 
Journal of Behavioral Medicine, 16, 259-268. doi:10.1007/s12529-009-9032-X

[22] Diener, E., Oishi, S. and Lucas, R.E. (2003) Personality, culture, and subjective well-being: Emotional and congnitive evaluations of life. Annual Review of Psychology,
54, 403-425.

doi:10.1146/annurev.psych.54.101601.145056

[23] McDowell, I. (2010) Measures of self-percieved wellbeing. Journal of Psychosomatic Research, 69, 69-79. doi:10.1016/j.jpsychores.2009.07.002 